\title{
Effects of whole body vibration exercise on lumbar-abdominal muscles activation for patients with chronic low back pain
}

\author{
Yulin Dong ${ }^{1}$, Huifang Wang ${ }^{2}$, Yan Zhu' ${ }^{1}$, Binglin Chen ${ }^{3}$, Yili Zheng ${ }^{4}$, Xiaochen Liư ${ }^{4}$, Jun Qiao ${ }^{\text {* }}$ (D) and
} Xueqiang Wang ${ }^{4^{*}}$ (D)

\begin{abstract}
Background: Whole body vibration (WBV) training as an intervention method can cure chronic low back pain (CLBP). Different WBV parameters exert different effects on lumbar-abdominal muscle performance. Currently, there is a lack of study researched the influence of WBV training on patients with CLBP by lumbar-abdominal muscle activity. Therefore, this study aimed to investigate how WBV and exercise and their interactions influence lumbarabdominal muscle activity in patients with CLBP.
\end{abstract}

Methods: a group of ambulatory patients with chronic low back pain. Muscle activities of the multifidus (MF), erector spinae (ES), abdominal oblique externus muscle (AOE) and the rectus abdominis muscle (RA) were measured by surface electromyography, whereas participants performed 4 different exercises (single bridge, plank, side stay and $\mathrm{V}$ crunch) during three whole body vibration conditions and a no-vibration condition in a single experimental session.

Results: Compared with the same exercises without whole body vibration, muscle activity increased when whole body vibration was added to the exercises. MF; the WBV frequency $(P=0.002$, ) and exercise $(P<0.001)$ presented significant effects on the root mean square of MF, whereas exercise * frequency $(P=0.044)$ also resulted in significant interaction effects. ES: the significant differences were detected at WBV frequency $(P<0.001)$, exercise $(P<0.001)$, the interaction effect of exercise and frequency $(P=0.225)$ was no significant. RA: the significant difference was detected at WBV frequency $(P=0.018)$, the effect of exercise $(P=0.590)$ and the exercise ${ }^{*}$ frequency interaction $(P=0.572)$ were no significant. AOE: the significant difference was detected at WBV frequency $(P<0.001)$, the effect of exercise $(P=0.152)$ and the exercise * frequency interaction $(P=0.380)$ were no significant.

Conclusion: Adding whole body vibration to exercise could increase muscle activation of lumbar-abdominal muscle in patients with CLBP. The optimum frequency for lumbar-abdominal muscles is $15 \mathrm{~Hz}$. The best exercises include plank for multifidus and erector spinae, $\mathrm{V}$ crunch for rectus abdominis and single bridge for abdominal oblique externus.

(Continued on next page)

\footnotetext{
*Correspondence: qiaojun19791117@126.com; qiang897@163.com

'Department of Treatment, The Second Rehabilitation Hospital of Shanghai,

25 Changjiang RD, Shanghai, China

${ }^{4}$ Department of Sport Rehabilitation, Shanghai University of Sport, 399

Changhai RD, Shanghai, China

Full list of author information is available at the end of the article
}

(c) The Author(s). 2020 Open Access This article is licensed under a Creative Commons Attribution 4.0 International License, which permits use, sharing, adaptation, distribution and reproduction in any medium or format, as long as you give appropriate credit to the original author(s) and the source, provide a link to the Creative Commons licence, and indicate if changes were made. The images or other third party material in this article are included in the article's Creative Commons licence, unless indicated otherwise in a credit line to the material. If material is not included in the article's Creative Commons licence and your intended use is not permitted by statutory regulation or exceeds the permitted use, you will need to obtain permission directly from the copyright holder. To view a copy of this licence, visit http://creativecommons.org/licenses/by/4.0/ The Creative Commons Public Domain Dedication waiver (http://creativecommons.org/publicdomain/zero/1.0/) applies to the data made available in this article, unless otherwise stated in a credit line to the data. 
(Continued from previous page)

Clinical registration: Trial registration: ChiCTR-TRC-13003708. Registered 19 October 2013.

The code of ethical approval: 2014008.

Keywords: Vibration, Low back pain, Abdominal muscles

\section{Background}

Whole body vibration (WBV) has been common among scientific studies in the last decade. WBV has emerged as a new type of neuromuscular training method that can effect muscle strength and power [1], electromyographic activity [2], neuromuscular reflex [3], and postural control [4].

WBV training has a wide range of vibration parameters, including vibration types (alternating and vertical vibrations), frequency, amplitude, time and body posture. Several clinical experiments have investigated the influence of different WBVs on lower limb muscle activation; the results indicated that different exercises induced varying degrees of leg muscle activity $[2,5,6]$. Low-intensity WBV training is more suitable for muscle activation than high-intensity WBV [2]. Muscle activation also depends on the interaction between frequency and body position [7]. According to these studies, different parameters exert different effects on muscle performance.

As for lumbar-abdominal muscles, combining routine lumbar and abdominal exercises, WBV training in healthy adults showed that static trunk muscle exercises could induce a low-to-moderate muscle activation [8]. Different parameters of WBV training could affect lumbar-abdominal muscle activities in healthy adults $[9,10]$. Richard, et al., reported that they found significantly more average and peak-to-peak estimated torque at almost all frequencies for vibration vs staticiitting [11].High vibration frequencies can lead to enhanced exercise benefits within an appropriate frequency range for lumbar-abdominal muscle in healthy adults [10]. Muscle activity during Stochastic resonance whole body vibrations (SR-WBV) is reasonably low and comparable to core strength stability exercises, sensorimotor training and "abdominal hollowing" in water [12]. In addition, flexor muscle weakening and imbalance of muscle strength are important cause of chronic low back pain (CLBP) $[13,14]$. Strengthening lumbar muscles is an important objective of CLBP treatment [15]. Muscle activation is one of the main indicators to evaluate muscle performance [10]. Therefore, lumbar-abdominal muscle activation is also closely related to chronic low back pain (CLBP). Several clinical intervention studies reported that WBV training as an intervention method can reduce CLBP effectively and improve quality of life [16-18]. To our knowledge, no study researched the influence of WBV training on patients with CLBP by lumbar-abdominal muscle activity. Furthermore, no standard clinical guidelines are available for WBV training in relation to curing CLBP.

Several clinical experiments have reported the effect of WBV on muscle activation [2, 19], and most of the results indicated that surface electromyography (sEMG) amplitude increases by adding vibration to multiple exercises [20]. sEMG of lumbar-abdominal muscle represents a kind of bioelectrical signal, that is the sum of applicable signal in time and space. To a certain extent, sEMG can reflect neuromuscular activity. One of the sEMG indicators is root mean square (RMS) amplitude, which is the instantaneous RMS amplitude of EMG over a period of time [21]. RMS can be used to evaluate the level of lumbar-abdominal muscle activity under different movements, loads and frequencies [22, 23].

To solve these knowledge gaps, this study observed how different WBV conditions affected the lumbar-abdominal muscle activation in patients with CLBP. The study hypothesised the following: (1) WBV training with exercises can increase muscle activation compared with the same exercise without WBV; (2) different frequencies cause varying effects on muscles, with higher frequencies inducing higher neuromuscular activity than lower WBV frequencies; (3) different exercises exert various effects on specific lumbar-abdominal muscles; (4) a significant interaction occurs between exercise and vibration frequency in lumbar-abdominal muscle activation.

\section{Methods \\ Participants}

This study designed an clinical research with repeated measures $[2,24]$. Twenty-one participants were recruited from the Shangti orthopaedic hospital and the second rehabilitation hospital in Shanghai. All the subjects were 20 years old or over and had CLBP. The inclusion criteria were:(1) Ages from18 to 60 years old, (2) persistent pain for 3 months at least or intermittent pain for 3 times a week over a period of 3 months, (3) there were no anaesthesia and abnormal lower limb reflexes. Exclusion criteria were: (1) undergone previous surgery, dislocation, fracture, rheumatoid arthritis, ankylosing spondylitis and disc pathology (2) organic diseases, metabolic diseases, cardiovascular diseases, progressive neurological deficits or sever osteoporosis, (3) pregnant or lactating, (4) sever hypertension, (5) Numerical Pain Scale (NPS, from 1 to 10) over 8, (6) did WBV exercise in last 3 months, (7) other diseases, 
advisable to participate this study based on the judgment of patients or physicians, (8) individuals who had any of the following situations will be excluded.

Prior to inclusion, we asked for all the participants to inform consent. Before attending the study, all participants would do a questionnaire about the following details: basic information, NPS, oswestry disability index (ODI) and daily exercise habits.

\section{Experimental protocol}

The study was approved by the Ethics Committee of Shanghai University of Sport. We carried out all the experimental programs in the same laboratory and collect complete data of each subjects in one single experiment session.

A WBV machine generating vertical vibrations was used (AV-009; BODYGREEN, Taiwan, China) at a vibration frequency range of $5-35 \mathrm{~Hz}$ and amplitude of $2 \mathrm{~mm}$. The three frequencies $(5 \mathrm{~Hz}, 10 \mathrm{~Hz}$ and $15 \mathrm{~Hz})$ and one amplitude $(2 \mathrm{~mm})$ were selected in this study. Also, a control condition without WBV was also tested. All participants were demanded to practice 4 kinds of exercises, producing 16 testing conditions in all. These exercises were as follows (Fig. 1). For single bridge, the participants lay on the platform, with one leg bent over the vibration platform and the other leg lifted straight off the platform. The patients extended their hip joint and back off the platform. For planking, both elbows were placed on the vibration platform, whereas the back, hip and both legs stay straight off the platform. For the side stay, the participants lay on their side on the platform, with a single elbow placed on the vibration platform. For $\mathrm{V}$ crunching, the patients rolled up their abdomen, pushed their shoulders towards the pelvis, and situated their upper hip on the vibration platform. The participants were randomly subjected to 16 testing conditions. Before data collection, all the participants must be familiarized with all the target exercises. Participants were instructed to perform each exercise under three vibration frequencies and no vibration. In total, each exercise was performed for $130 \mathrm{~s}$ (each exercise condition lasted for $10 \mathrm{~s}$, with a $30 \mathrm{~s}$ break between two frequencies); the patients rested for 5 min between two exercises. During the exercises, the experimenter recorded the lumbar-abdominal muscle sEMG signals of the participants. Each participant practiced the sequence of the vibration frequency and exercises randomly.

EMG data were collected by MyoResearch XP Master Software Version 1.07.17(Noraxon Inc., Scottsdale, USA) with sampling frequency of $1500 \mathrm{~Hz}$. After we use medical alcohol and razor to reduce skin impedance. The electrodes (Silver chloride, Shangqiankang medical equipment co. LTD) were put in place referring to the updated introduction for sEMG [25].We choose the lumbar and abdominal muscles on the side of severe pain were multifidus (MF), erector spinae (ES), rectus abdominis (RA) and abdominis oblique externus (AOE) respectively. The placement of the electrode is as follows: (1) MF: $2-3 \mathrm{~cm}$ from the midline at the level of L5, putted on and aligned with a line from caudal tip posterior spina iliaca superior to the interspace between L1 and L2; (2) ES: An electrode was placed $2 \mathrm{~cm}$ apart from the midpoint of the bilateral iliac ridge connection; (3) RA: $2-3 \mathrm{~cm}$ lateral from the midline on the second segment of the muscle; (4) AOE: at half of the line from the anterior spina iliaca superior and the tip of the 11th rib [26].
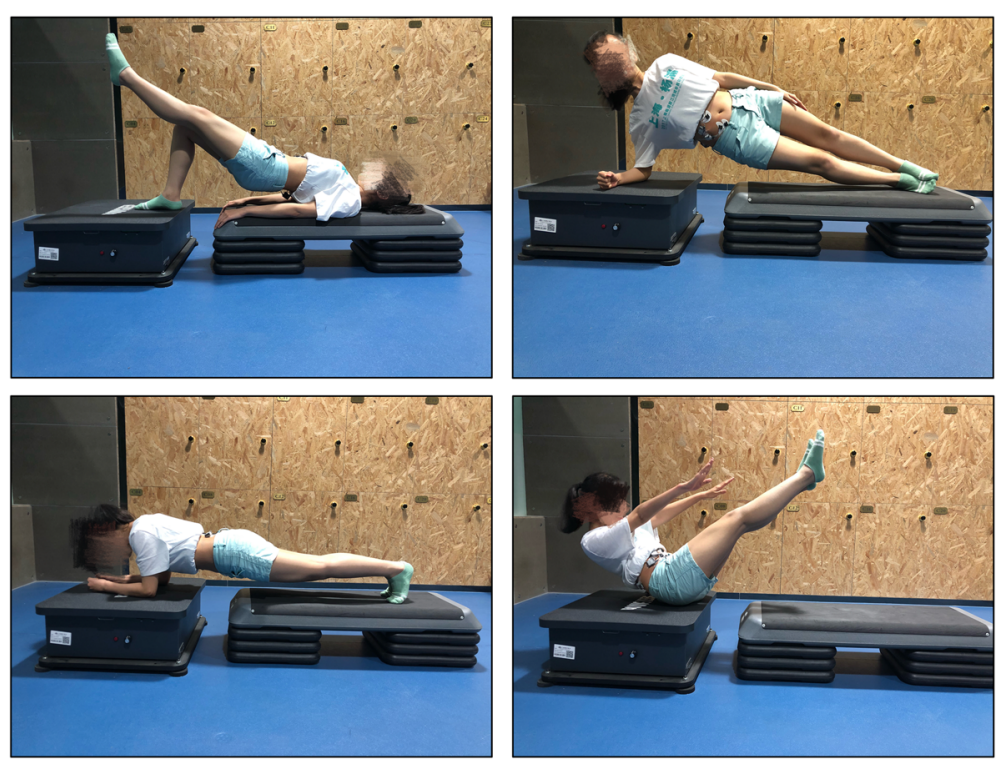

Fig. 1 Four exercises on the platform: single bridge, plank, side stay and V crunch 


\section{Data analysis}

All original data were performed by MyoResearch XP Master Software Version 1.07.17 (Noraxon Inc., Scottsdale, USA). First, the original EMG signals were processed with a 10 and $500 \mathrm{~Hz}$ noise by utilizing Mat Lab [9]. For the four exercises, the middle $5 \mathrm{~s}$ of the data was used to calculate the EMG root mean square (EMGrms), which represents the magnitude of muscle activity. A higher RMS value indicates more muscle activity. For the standardization of sEMG data, the value of RMS under WBV was compared with that under no-WBV, which was considered as the degree of muscle activity during WBV training [2].

\section{Statistical analysis}

Statistical analyses were conducted with SPSS 17.0 and Microsoft Excel 2007. Two-way ANOVA with repeated measures was used to explore the effect of different WBV conditions for each muscle. If the sphericity assumption (Mauchly's test) was violated, we would use the Greenhouse-Geisser epsilon adjustment. The Shapiro-Wilk test was used to assess the normality of the descriptive data. Statistical analyses were conducted as follows: (1) the main effect of frequency was determined by any conspicuous difference in muscle activation observed amidst the three different frequencies measured; (2) the main effect of exercise was determined by any conspicuous difference in muscle activation observed amidst the 4 different exercises measured; (3) and the frequencies $x$ interaction effect: whether any the interaction effect of WBV frequencies and exercise forms. F-ratio (F) represents the each of main effects, and then it is relative to a critical F-value to evaluate its significance. We determined the muscle activation that was deeply influenced by WBV and used post-hoc analysis (paired t-test) with Bonferroni adjustment for evaluation. The statistical significance level was set at $p<0.05$.

\section{Results}

\section{Demographics}

Twenty-one patients with CLBP attended in the study (11 men, mean age, $22.4 \pm 2.62$ years). All the patients were recorded demographics by the same physical therapist (Table 1), and all the statistics expresses by mean and standard deviation (SD). Table 2 showed the muscle activities during different exercises with no-WBV/WBV training.

Table 1 Demographics of participants (Mean \pm SD)

\begin{tabular}{ll}
\hline & Mean \pm SD \\
\hline Age, year & $22.4 \pm 2.62$ \\
Gender (Women/Man) & $10 / 11$ \\
Weight, kg & $61 \pm 9.45$ \\
Height, cm & $168.86 \pm 8.3$ \\
NPS(0-10) & $3 \pm 1$ \\
ODI (0-100) & $20.77 \pm 3.73$ \\
\hline
\end{tabular}

\section{Muscle activity of Multifidus}

The value of RMS of MF increased compared with that under the same exercise without WBV (total average, 208.7\%). The significant differences were detected at WBV frequency $(P=0.002, \mathrm{~F}=10.736)$, exercise $(P<0.001$, $\mathrm{F}=10.799)$ and the exercise * frequency interaction $(P=$ $0.044, F=3.328$ ). It showed that the effect of WBV frequency on the value of RMS of MF was related to exercise. Then, the RMS of MF was highest when the WBV condition was in plank exercise with $15 \mathrm{~Hz}$ (Fig. 2).

\section{Muscle activity of erector Spinae}

The value of RMS of ES increased compared with that under the same exercises without WBV (The total average, 190\%). The significant differences were detected at WBV frequency $(P<0.001, \mathrm{~F}=12.958)$, exercise $(P<$ $0.001, F=5.967)$. The interaction effect of exercise and frequency $(P=0.225, \mathrm{~F}=1.388)$ on $\mathrm{ES}$ was no significant, indicating that the effect of WBV on ES was not related these factors. Then, using paired comparisons between exercises, the result found that there were significant among single bridge, plank and the $\mathrm{V}$ crunch. The highest muscle activation was induced by plank exercise. In the same way, $15 \mathrm{~Hz}$ was the best frequency for muscle activation (Fig. 3).

\section{Muscle activity of rectus Abdominis}

The value of RMS of RA increased compared with that under the same exercises without WBV (The total average, 247.1\%). The significant difference was detected at WBV frequency $(\mathrm{F}=6.555, P=0.018)$. The effect of exercise $(\mathrm{F}=0.513, P=0.590)$ and the exercise * frequency interaction $(\mathrm{F}=0.525, P=0.572)$ were no significant, expressing that effect of WBV frequencies on RA was not relate with exercises. Then, we found $15 \mathrm{~Hz}$ can induce highest degree of muscle activation by paired comparisons (Fig. 4). Among the exercises, there was significance between $\mathrm{V}$ crunch and plank, $\mathrm{V}$ crunch can induce highest degree of muscle activation.

\section{Muscle activity of abdominal oblique Externus}

The value of RMS of AOE increased compared with that under the same exercises without WBV (The total average, 206.8\%). The significant difference was detected at WBV frequency $(\mathrm{F}=15.294, P<0.001)$. The effect of exercise $(F=2.010, P=0.152)$ and the exercise * frequency interaction $(\mathrm{F}=0.975, P=0.380)$ were no significant, it showed that effect of WBV frequencies on RA was not relate with exercises. Then, we found $15 \mathrm{~Hz}$ can induce highest degree of muscle activation by paired comparisons (Fig. 5). Among the exercises, there was significance between single bridge and plank. Single bridge can induce highest degree of muscle activation. 
Table 2 Muscle activation measured in the no-vibration/vibration condition (RMS, Mean \pm SD)

\begin{tabular}{|c|c|c|c|c|c|}
\hline & $\begin{array}{l}\text { Frequency } \\
\text { (HZ) }\end{array}$ & Single bridge $(\mu \mathrm{V})$ & $\begin{array}{l}\text { Plank } \\
(\mu \mathrm{V})\end{array}$ & Side stay $(\mu \mathrm{V})$ & $\begin{array}{l}V \text { crunch } \\
(\mu \mathrm{V})\end{array}$ \\
\hline \multirow[t]{4}{*}{ Multifidus muscle } & 0 & $67.45 \pm 6.15$ & $13.15 \pm 4.67$ & $13.64 \pm 3.23$ & $23.72 \pm 4.06$ \\
\hline & 5 & $70.56 \pm 5.61$ & $24.53 \pm 4.75$ & $22.14 \pm 3.16$ & $48.51 \pm 6.25$ \\
\hline & 10 & $93.45 \pm 6.39$ & $32.02 \pm 3.22$ & $27.13 \pm 4.08$ & $52.16 \pm 5.22$ \\
\hline & 15 & $84.47 \pm 4.28$ & $45.02 \pm 5.43$ & $34.37 \pm 4.85$ & $56.72 \pm 4.01$ \\
\hline \multirow[t]{4}{*}{ Erector spinae muscle } & 0 & $67.28 \pm 5.91$ & $11.65 \pm 3.22$ & $13.13 \pm 3.59$ & $35.60 \pm 9.70$ \\
\hline & 5 & $70.87 \pm 5.82$ & $17.18 \pm 2.18$ & $18.65 \pm 2.63$ & $64.73 \pm 6.12$ \\
\hline & 10 & $74.39 \pm 8.52$ & $27.51 \pm 3.90$ & $22.66 \pm 2.48$ & $71.23 \pm 2.23$ \\
\hline & 15 & $80.21 \pm 3.24$ & $33.65 \pm 2.98$ & $25.50 \pm 1.68$ & $92.56 \pm 5.36$ \\
\hline \multirow[t]{4}{*}{ Rectus abdominis muscle } & 0 & $11.26 \pm 1.86$ & $88.62 \pm 7.50$ & $23.02 \pm 4.72$ & $89.47 \pm 8.03$ \\
\hline & 5 & $20.09 \pm 2.63$ & $98.23 \pm 5.23$ & $28.34 \pm 4.10$ & $163.93 \pm 7.02$ \\
\hline & 10 & $27.43 \pm 3.57$ & $135.91 \pm 3.60$ & $36.93 \pm 3.69$ & $191.24 \pm 8.10$ \\
\hline & 15 & $35.13 \pm 3.73$ & $171.52 \pm 4.25$ & $43.96 \pm 4.32$ & $231.4 \pm 10.37$ \\
\hline \multirow[t]{4}{*}{ Obliques externus muscle } & 0 & $16.63 \pm 2.97$ & $39.27 \pm 3.92$ & $21.41 \pm 5.68$ & $42.95 \pm 4.95$ \\
\hline & 5 & $25.58 \pm 1.55$ & $56.7 \pm 5.15$ & $28.35 \pm 4.22$ & $73.98 \pm 6.25$ \\
\hline & 10 & $41.02 \pm 3.30$ & $66.98 \pm 2.89$ & $40.15 \pm 2.02$ & $112.92 \pm 3.65$ \\
\hline & 15 & $47.56 \pm 4.94$ & $72.12 \pm 5.48$ & $49.74 \pm 4.03$ & $101.64 \pm 10.08$ \\
\hline
\end{tabular}

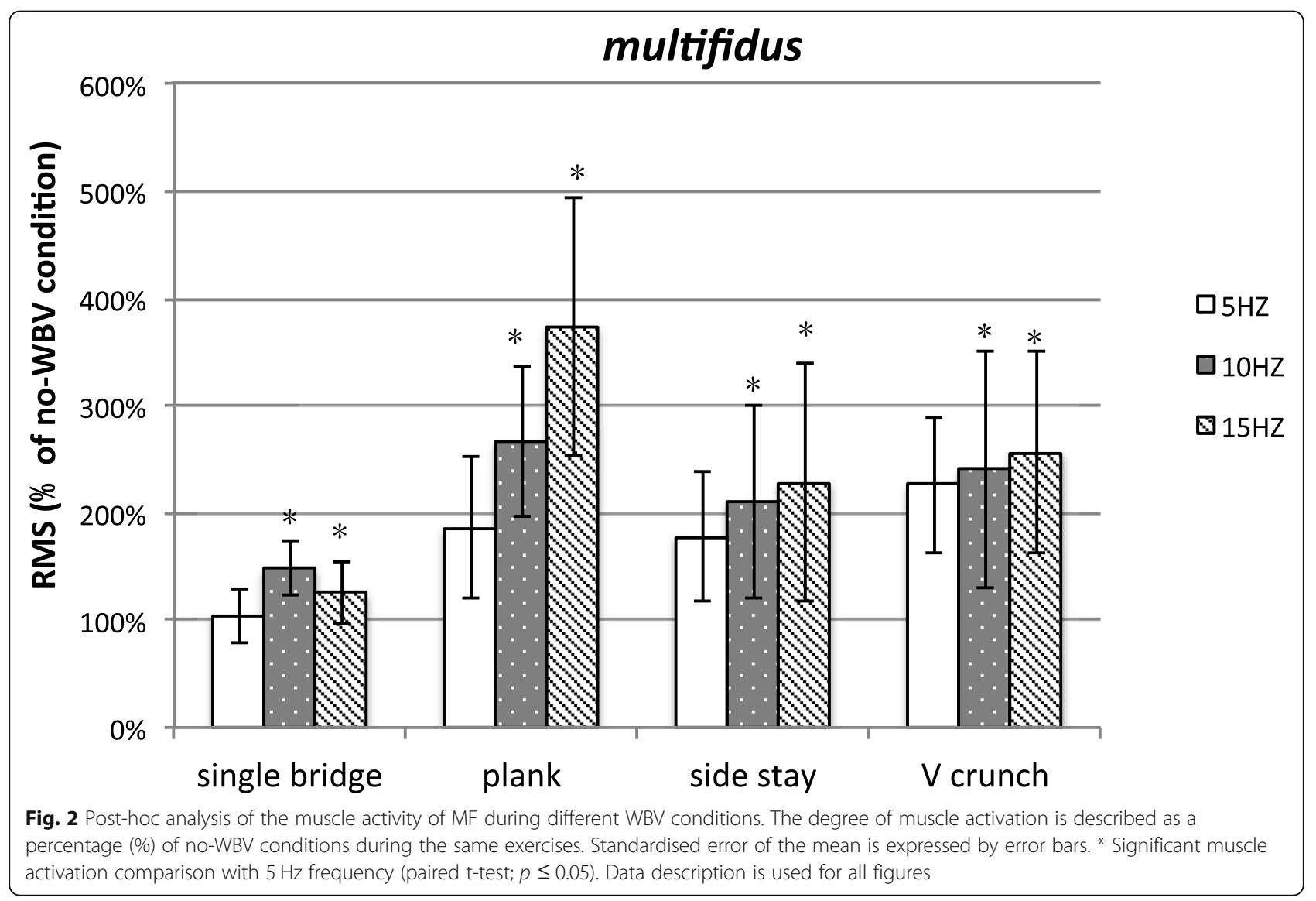



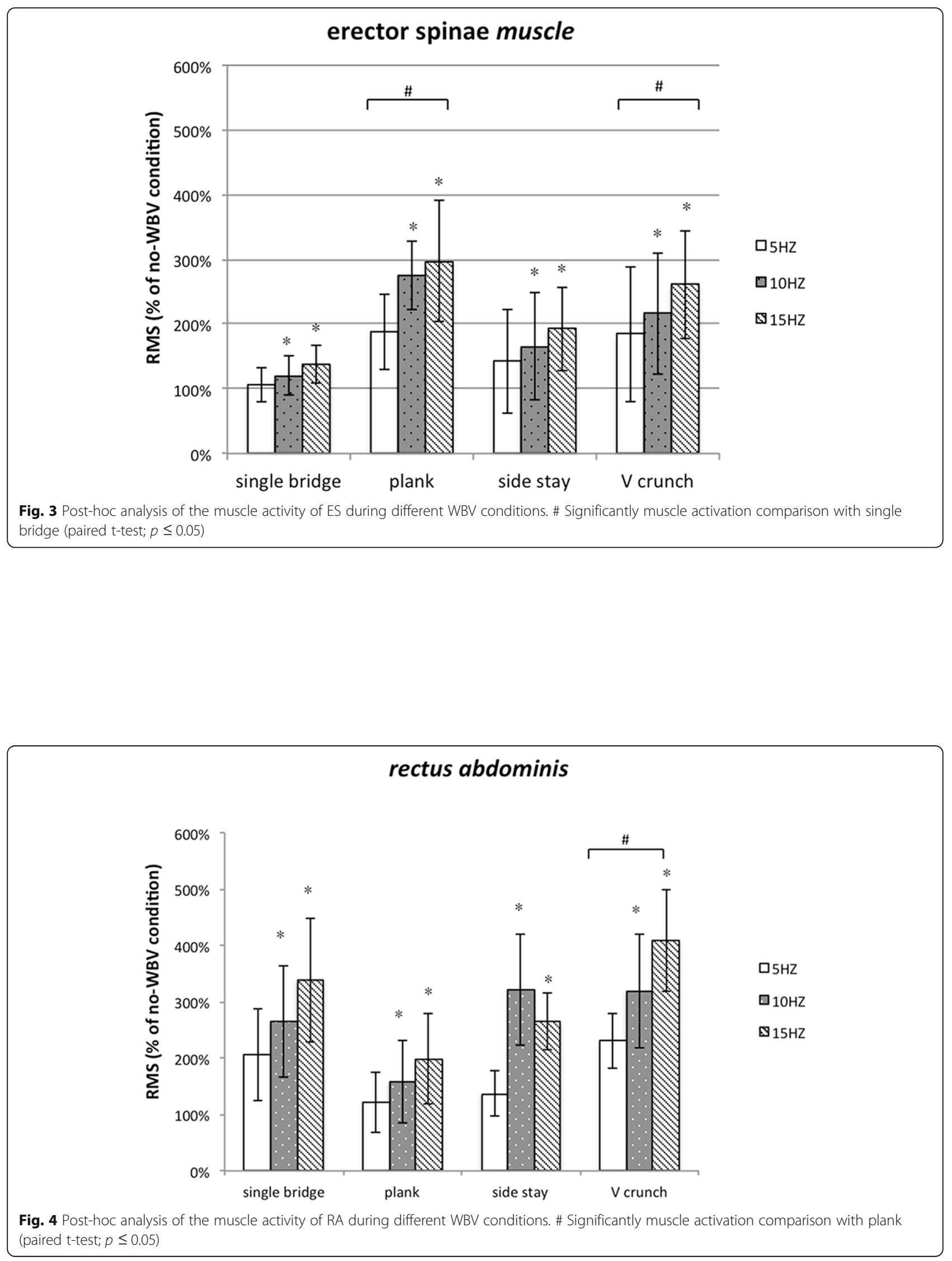


\section{abdominis obliquus externus}

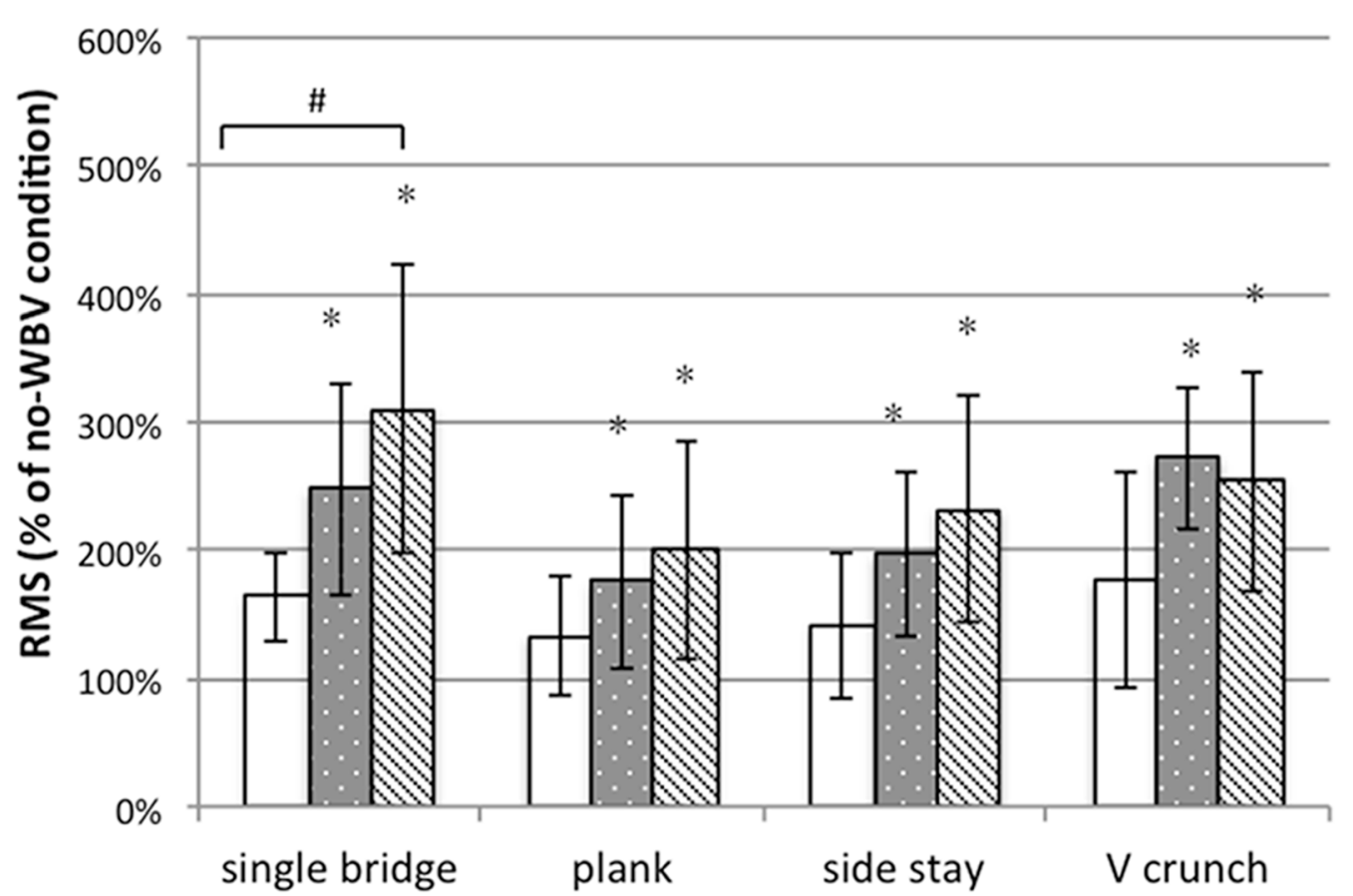

Fig. 5 Post-hoc analysis of the muscle activity of AOE during different WBV conditions. \# Significantly muscle activation comparison with plank (paired t-test; $p \leq 0.05$ )

\section{Discussion}

This study aimed to identify the effect of WBV on lumbar abdominal muscle activities in patients with CLBP. Using different combinations of vibration parameters, this study could provide important ideas for clinical treatment or research to attention on the interaction effects of exercise and frequencies.

\section{Effect of WBV on lumbar-abdominal muscle activation}

Results of our study powerfully supported the first hypothesis that adding WBV to exercises could increase muscle activation in MF (the total average, 208.7\%), ES (the total average, 190\%), AOE (the total average, 206.8\%) and RA (the total average, 247.1\%). In general, our study showed that muscle activation of patients with CLBP was similar to that of previous studies on healthy adults $[9,26]$. For example, the authors evaluated the trunk muscle activation in different static exercises on the vibrating platform, and their results revealed that WBV led to increased muscle activation by $1.6 \% \pm 1.4 \%$ maximal voluntary contraction (MVC) in MF and $46.4 \% \pm 14.9 \% \mathrm{MVC}$ in RA [26]. These data showed that WBV could induce lumbar-abdominal muscle activity. Other factors would affect the degree of muscle activation [9]. For example, healthy individuals performed single bridge exercise with WBV training, resulting in higher degree of ES activation than MF activation [26]. This result differed from the findings of our study, in which CLBP patients conducting single bridge exercise induced the highest AOE activation.

Considering all the evidence gathered from these findings and previous studies, WBV training could be popular among individuals with poor muscle strength, and long-term training would result in more gains [27]. Second, the effect of WBV on muscle activation depends on the body position, types of participants and vibration frequency [2]. Third, we should be rigorous on comparing different populations. The EMG presents individual differences, such as skin interference, body posture and electrode position. Given these uncontrollable factors, we should conduct data standardisation according to certain reference values, such as the value of sEMG in no-WBV condition or MVC. This design uses the value of sEMG in no-WBV condition as reference to ensure reliable conclusions [2].

\section{Effect of different frequencies on lumbar-abdominal muscle activation}

The results of this study revealed that a higher frequency $(15 \mathrm{~Hz})$ induces higher neuromuscular activity than lower WBV frequencies (5 and $10 \mathrm{~Hz}$ ), thus supporting the second hypothesis. 
During WBV, the body of an individual is stimulated by appropriate mechanical stimuli. The related mechanism possibly utilises mechanical vibration and external resistance loads to stimulate muscle spindles; this training method improves neuromuscular function by inducing elevated muscle contractile activities and central nervous system adaptation [28]. These study findings were similar to those of several previous studies. For example, Brigitte et al. reported that vibration led to increased RMS value of MF by $26 \%$ when compared with that under no vibration [26]. Xueqiang et al. performed a clinical study about the effect of different platforms on lumbar-abdominal muscle activation. They reported that unstable platforms could induce higher activation than stable ones when healthy subjects performed various kinds of exercise [23]. Desai et al. studied the rate of lumbar-abdominal muscle activation (RMS\% MVC) in patients with CLBP and healthy people; the results demonstrated that the unstable platform is a good choice for inducing muscle activation [29]. The above evidence all suggest that stimulation of unstable planes or vibration platform increases muscle activity. The practical significance of RMS is as a statistical characteristic of EMG showing muscle activities [21]. When the body is on the vibration platform, the muscle induces more muscle spindles to resist external loads and maintain body balance. To a certain extent, a higher RMS value indicates more muscle activity. Our results showed that high vibration frequency is better for lumbar-abdominal muscle in patients with CLBP than low vibration frequency.

Study have shown the effect of different vibration frequencies on the activation of lumbar and abdominal muscles, revealing no significant differences between different vibration frequencies during bridge exercise [30]. The effect of WBV training (less than $20 \mathrm{~Hz}$ ) on lumbar and abdominal muscles could increase the muscle strength of the extensor muscle, whereas 40 $\mathrm{Hz}$ would decrease the extensor muscle endurance [8]. Moreover, the I $\alpha$ inhibitory neurons in the drafting state could be activated by WBV (Less than or equal to $5 \mathrm{~Hz}$ ), which could promote the reduction of single synaptic reflexes and relax tensed muscles [31]. Highintensity vibration would forcefully expose the muscle spindles to vibration stimulation, producing an inhibitory reflex, blocking muscle spindle transmitters, reducing the sensitivity of muscle spindle and causing muscle fatigue $[32,33]$. The vibration frequency of lumbar abdomen is mostly below $20 \mathrm{~Hz}$, and the results showed that such value could relieve pain in patients with CLBP and reduce the dysfunction index $[16,34]$. In current studies, $15 \mathrm{~Hz}$ induces higher neuromuscular activity compared with $5 \mathrm{~Hz}$ and 10 $\mathrm{Hz}$. Considering the overall evidence, $15 \mathrm{~Hz}$ vibration frequencies can lead to enhanced exercise benefits.

\section{Effect of different exercises on lumbar-abdominal muscle activation}

Among the various exercises selected in this study, the optimum routines included plank for MF and ES, single bridge for AOE and V crunch for RA. Different muscles perform differently during exercises considering their own anatomical characteristics.

MF and ES are kinds of back muscles that maintain the spinal stability and balance. During plank exercise, the muscles are in static equal-length contraction, which would activate as many muscles, especially the deep stabilizing muscles such as the MF, as possible to maintain the stability of the spine [26]. MF contains rich proprioceptive receptors that enable the performance of delicate movements. When the spine suddenly becomes imbalanced, the MF would contract before the larger muscle groups adjust the displacement of individual vertebral segments. MF is a fundamental part to maintaining the normal biometric lines of the spine and enhancing lumbar stability $[35,36]$. ES covers the lumbar and thoracic region; it is a large muscle group that maintains the stability of the spine. ES is a primary muscle for plank; both sides of ES contract to resist body gravity and keep the spine in a stable condition [36]. Previous studies showed that side stay and bridge exercises are good for back muscles, such as MF and ES, in WBV condition [26]. The most possible explanation for the conflicting results of this experiment could be the interaction effects between vibration frequencies and exercises on muscles. In general, WBV induced the greatest back muscle activation during plank training.

RA and AOE are both lumbar-abdominal muscles. During V crunch exercise, both ends of the body leave the ground, and all the gravity is concentrated on the abdominal muscles. These muscles require more muscle spindles to resist the load. On the other hand, the action of the $\mathrm{V}$ crunch is a centripetal contraction, whereas the RA is an active muscle requiring more strength. Atsushi et al. observed the effects of different platforms on trunk muscles during core stability training. The results showed that $\mathrm{V}$ crunch induced the highest RA activities on an unstable platform [37]. Vera-Garcia et al. observed that the degree of RA activation reached more than $10 \%$ of that of AOE under the $\mathrm{V}$ crunch exercise with unstable conditions [38]. Our findings were similar to those of previous studies. AOE is a large, thin and irregularly quadrilateral muscle located on the side of abdomen. During single bridge, one side of the upper limb and lower limb was off the ground; the AOE would then undertake more tasks to prevent the body from tilting. Furthermore, single bridge exercise induces more activities on AOE when compared with other exercises [39]. Therefore, in the case of WBV training, RA in the action of $\mathrm{V}$ crunch and AOE in the action of single bridge 
showed the highest value of RMS, implying that the $\mathrm{V}$ crunch and single bridge could better activate abdominal muscles.

\section{Clinical implications}

Some clinical implications were provided in our study. First, WBV can effectively induce muscle activation in patients with CLBP, indicating that it could be an effective assisted intervention to improve muscle performance, such as muscle strength, proprioception and flexibility $[40,41]$. Second, the different WBV parameters have different effects on the lumbar-abdominal sEMG. Exercise, frequency and their interactions should be considered during WBV training of CLBP patients. We determined the best combination of WBV intensity at $15 \mathrm{~Hz}$ and 2 $\mathrm{mm}$ and plank or single bridge or $\mathrm{V}$ crunch exercises. If you want to improve back muscle performance, Plank or single bridge should be the more preferred choice for these individuals. If you want to improve abdominal muscle performance, $\mathrm{V}$ crunch would be a good choice.

\section{Limitations}

First, the results of this study could only be generalised to younger CLBP patients and could not represent all age groups with CLBP. Second, the selection of exercise featured certain limitations. Future research can expand the range of movements and observe the effect of different frequencies on the muscles in the case of dynamic movements. Third, amplitudes and frequencies are important factors for the effect of WBV training. Thus, future studies should include different amplitudes and additional frequencies.

\section{Conclusion}

Adding WBV to exercise could increase muscle activation of lumbar-abdominal muscle in patients with CLBP. High vibration frequencies can lead to enhanced exercise benefits within an appropriate frequency range, and different exercises have diverse effects on various muscles. Our results revealed that $15 \mathrm{~Hz}$ induces higher neuromuscular activity than lower WBV frequencies (5 and $10 \mathrm{~Hz}$ ). As for all lumbar-abdominal muscles, plank is suitable for the back muscles, single bridge for $\mathrm{AOE}$ and $\mathrm{V}$ crunch for RA.

\footnotetext{
Abbreviations

WBV: Whole body vibration; CLBP: Chronic low back pain; LBP: Low back pain; MF: Multifidus; ES : Erector Spinae; AOE: Abdominal Oblique Externus; RA: Rectus Abdominis; sEMG: Surface Electromyography; RMS: Root Mean Square
}

\section{Acknowledgements}

The author (YL.D) gratefully acknowledges the National Natural Science Foundation of China (81501956, 81871844), Fok Ying-Tong Education Foundation of China (161092), Shanghai Municipal Commission of Health and Family Planning (201840346) and Shanghai Key Lab of Human Performance (Shanghai University of Sport) (no: 11DZ2261100).

\section{Authors' contributions}

JQ and XQW developed the study design. XCL and HFW searched for eligible participants. XQW and JQ performed the training sessions. YLZ, XCL and HFW collection and assembly of data. BLC and $Y Z$ performed the statistical analysis. YLD wrote the first draft of the manuscript. YLD, YLZ, JQ and $\mathrm{XQW}$ revised the manuscript. All authors have read and approved the manuscript.

\section{Funding}

The author(s) disclosed receipt of the following financial support for the research, authorship and/or publication of this article: This work was supported by the Scientific research project of Shanghai Health Committee (20194Y0488); National Natural Science Foundation of China (81501956, 81871844); Fok Ying-Tong Education Foundation of China (161092); Shanghai Municipal Commission of Health and Family Planning (201840346); Shanghai Key Lab of Human Performance (Shanghai University of Sport) (no: 11DZ2261100); State Physical Culture Administration (QG2018030); Key construction projects of Baoshan health and Family Planning Commission (BSZK-2018-A01);"Shu Guang" project supported by Shanghai Municipal Education Commission and Shanghai Education Development Foundation.

\section{Availability of data and materials}

The datasets used and/or analysed during the current study are available from the corresponding author on reasonable request.

Ethics approval and consent to participate

This research was approved by the Ethics Committee of Shanghai University of Sport.

Participants were informed of the experimental procedures and risks and provided their written informed consent prior to attending several

familiarisation sessions.

Consent for publication

Not applicable.

\section{Competing interests}

The author(s) declared no potential conflicts of interest with respect to the research, authorship, and/or publication of this article.

\section{Author details}

'Department of Treatment, The Second Rehabilitation Hospital of Shanghai, 25 Changjiang RD, Shanghai, China. ${ }^{2}$ Yang Zhi Affiliated Rehabilition Hospital of Tongji, Shanghai, China. ${ }^{3}$ The Second School of Clinical Medicine, Xuzhou Medical University, Xuzhou, Jiangsu, China. ${ }^{4}$ Department of Sport Rehabilitation, Shanghai University of Sport, 399 Changhai RD, Shanghai, China.

Received: 5 August 2020 Accepted: 2 December 2020

Published online: 10 December 2020

\section{References}

1. Jacobs PL, Burns P. Acute enhancement of lower-extremity dynamic strength and flexibility with whole-body vibration. J Strength Cond Res. 2009;23:51-7.

2. Lam FMH, Liao LR, Kwok TCY, Pang MYC. The effect of vertical whole-body vibration on lower limb muscle activation in elderly adults: influence of vibration frequency, amplitude and exercise. Maturitas. 2016;88:59-64.

3. Ahmadi M, Torkaman G, Kahrizi S, Ghabaee M, Arani LD. Does the acute and short-term effect of whole body vibration is the same on the H-reflex recruitment curve and agility? J Sport Rehabil. 2015;25(4):348-56.

4. Huang M, Tang CY, Pang M. Use of whole body vibration in individuals with chronic stroke: transmissibility and signal purity. J Biomech. 2018;73:80-91.

5. Ritzmann R, Gollhofer A, Kramer A. The influence of vibration type, frequency, body position and additional load on the neuromuscular activity during whole body vibration. Eur J Appl Physiol. 2013;113:1-11.

6. Hazell TJ, Jakobi JM, Kenno KA. The effects of whole-body vibration on upper- and lower-body EMG during static and dynamic contractions. Appl Physiol Nutr Metab. 2007:32:1156-63.

7. Di GR, Masedu F, Tihanyi J, Scrimaglio R, Valenti M. The interaction between body position and vibration frequency on acute response to whole body vibration. J Electromyogr Kinesiol. 2013;23:245-51. 
8. Ye J, Ng G, Yuen K. Acute effects of whole-body vibration on trunk muscle functioning in young healthy adults. J Strength Cond Res. 2014;28:2872-9.

9. Perchthaler D, Hauser S, Heitkamp HC, Hein T, Grau S. Acute effects of whole-body vibration on trunk and neck muscle activity in consideration of different vibration loads. J Sports Sci Med. 2015;14:155-62.

10. Chen B, Dong Y, Guo J, Zheng Y, Zhang J, Wang X. Effects of whole-body vibration on lumbar-abdominal muscles activation in healthy young adults: a pilot study. Med Sci Monit. 2019;25:1945-51.

11. Seroussi RE, Wilder DG, Pope MH. Trunk muscle electromyography and whole body vibration. J Biomech. 1989;22:219-29.

12. Blasimann A, Fleuti $U$, Rufener $M$, Elfering $A$, Radlinger L. Electromyographic activity of back muscles during stochastic whole body vibration. J Musculoskelet Neuronal Interact. 2014;14:311-7.

13. Elnaggar IM, Nordin M, Sheikhzadeh A, Parnianpour M, Kahanovitz N. Effects of spinal flexion and extension exercises on low-back pain and spinal mobility in chronic mechanical low-back pain patients. Spine (Phila Pa 1976). 1991;16:967-72

14. Langrana NA, Lee CK, Alexander H, Mayott CW. Quantitative assessment of back strength using isokinetic testing. Spine (Phila Pa 1976). 1984;9:287-90.

15. Handa N, Yamamoto H, Tani T, Kawakami T, Takemasa R. The effect of trunk muscle exercises in patients over 40 years of age with chronic low back pain. J Orthop Sci. 2000;5(3):210-6.

16. Rittweger J, Just K, Kautzsch K, Reeg P, Felsenberg D. Treatment of chronic lower back pain with lumbar extension and whole-body vibration exercise: a randomized controlled trial. Spine (Phila Pa 1976). 2002;27:1829-34.

17. Maddalozzo GF, Kuo B, Maddalozzo WA, Maddalozzo CD, Galver JW. Comparison of 2 multimodal interventions with and without whole body vibration therapy plus traction on pain and disability in patients with nonspecific chronic low Back pain. J Chiropr Med. 2016;15:243-51.

18. Wang $X Q$, Gu W, Chen BL, et al. Effects of whole-body vibration exercise for non-specific chronic low back pain: an assessor-blind, randomized controlled trial. Clin Rehabil. 2019;33:1445-57.

19. Avelar NC, Ribeiro VG, Mezencio B, et al. Influence of the knee flexion on muscle activation and transmissibility during whole body vibration. J Electromyogr Kinesiol. 2013;23:844-50.

20. Lienhard K, Vienneau J, Nigg S, Meste O, Colson SS, Nigg BM. Relationship between lower limb muscle activity and platform acceleration during whole-body vibration exercise. J Strength Cond Res. 2015;29:2844-53.

21. Vigotsky AD, Halperin I, Lehman GJ, Trajano GS, Vieira TM. Interpreting signal amplitudes in surface electromyography studies in sport and rehabilitation sciences. Front Physiol. 2017;8:985.

22. Callaghan JP, Dunk NM. Examination of the flexion relaxation phenomenon in erector spinae muscles during short duration slumped sitting. Clin Biomech. 2002;17:353-60.

23. Xia $B$, Xeuqiang $W$, Zhihao $L$, et al. The impact of using a swiss ball to exercise the lumbo-abdominal muscle. Chinese J Physical Med Rehabilitation. 2012;34:208-11.

24. Washington RD. Review of: foundations of clinical research applications to practice. 3rd ed; 2010.

25. Emmanuel ADM. Cram's introduction to surface electromyography, 2nd edition. Med Sci Sports Exerc. 2011;43:405.

26. Wirth B, Zurfluh S, Müller R. Acute effects of whole-body vibration on trunk muscles in young healthy adults. J Electromyogr Kinesiol. 2011;21:450-7.

27. Lam FMH, Lau RWK, Chung RCK, Pang MYC. The effect of whole body vibration on balance, mobility and falls in older adults: a systematic review and meta-analysis. Maturitas. 2012;72:206-13.

28. Slatkovska L, Alibhai SMH, Beyene J, Hu H, Demaras A, Cheung AM. Effect of 12 months of whole-body vibration therapy on bone density and structure in postmenopausal women: a randomized trial. Ann Inter Med. 2011;155:668-79.

29. Desai I, Marshall PW. Acute effect of labile surfaces during core stability exercises in people with and without low back pain. J Electromyogr Kinesiol. 2010;20:1155-62.

30. Kim TH, Choi HS. EMG Activities of Trunk and Lower Extremity Muscles Induced by Different Intensity of Whole Body Vibration During Bridging Exercise. PKT;2009;16:16-22.

31. Cochrane DJ, Stannard SR. Acute whole body vibration training increases vertical jump and flexibility performance in elite female field hockey players. Br J Sports Med. 2005;39:860-5

32. Ribot-Ciscar E, Rossi-Durand C, Roll JP. Muscle spindle activity following muscle tendon vibration in man. Neurosci Lett. 1998;258:147-50.
33. Rong L, Kaiwen J. Research Progress of Neuromuscular Fatigue in Physiology. Sports \& Science. 2001;03:34-6.

34. Yang J, Seo D. The effects of whole body vibration on static balance, spinal curvature, pain, and disability of patients with low back pain. J Phys Ther Sci. 2015;27:805-8

35. Aboufazeli M, Akbari M, Jamshidi AA, Jafarpisheh MS. Comparison of selective local and global muscle thicknesses in females with and without chronic low Back pain. Ortop Traumatol Rehabil. 2018;20:197-204.

36. Sions JM, Coyle PC, Velasco TO, Elliott JM, Hicks GE. Multifidi muscle characteristics and physical function among older adults with and without chronic low Back pain. Arch Phys Med Rehabil. 2017:98:51-7.

37. Imai A, Kaneoka K, Okubo Y, et al. Trunk muscle activity during lumbar stabilization exercises on both a stable and unstable surface. J Orthop Sports Phys Ther. 2010;40:369-75.

38. Vera-garcia FJ, Grenier SG, Mcgill SM. Abdominal muscle response during curl-ups on both stable and labile surfaces. Phys Ther. 2000;80:564-9.

39. Ekstrom RA, Donatelli RA, Carp KC. Electromyographic analysis of core trunk, hip, and thigh muscles during 9 rehabilitation exercises. J Orthop Sports Phys Ther. 2007;37:754-62.

40. Kinser AM, Ramsey MW, O'Bryant HS, Ayres CA, Sands WA, Stone MH. Vibration and stretching effects on flexibility and explosive strength in young gymnasts. Med Sci Sports Exerc. 2008;40:133-40.

41. Lai CC, Tu YK, Wang TG, Huang YT, Chien KL. Effects of resistance training, endurance training and whole-body vibration on lean body mass, muscle strength and physical performance in older people: a systematic review and network meta-analysis. Age Ageing. 2018;47:367-73.

\section{Publisher's Note}

Springer Nature remains neutral with regard to jurisdictional claims in published maps and institutional affiliations.

Ready to submit your research? Choose BMC and benefit from:

- fast, convenient online submission

- thorough peer review by experienced researchers in your field

- rapid publication on acceptance

- support for research data, including large and complex data types

- gold Open Access which fosters wider collaboration and increased citations

- maximum visibility for your research: over $100 \mathrm{M}$ website views per year

At $\mathrm{BMC}$, research is always in progress.

Learn more biomedcentral.com/submissions 